\title{
Measurement of Water Productivity in Seasonal Floodplain Beel Area
}

\author{
Md. Istiaque Hossain \\ Department of Fisheries \\ Faculty of Agriculture \\ University of Rajshahi \\ Bangladesh \\ Md. Mahmudul Alam* \\ School of Economics, Finance \& Banking \\ College of Business \\ Universiti Utara Malaysia \\ Malaysia \\ Email: rony000@gmail.com \\ Chamhuri Siwar \\ Institute for Environment and Development \\ Universiti Kebangsaan Malaysia \\ Malaysia \\ Mazlin Mokhtar \\ Institute for Environment and Development \\ Universiti Kebangsaan Malaysia \\ Malaysia \\ *corresponding author
}

\section{Citation Reference:}

Hossain, M.I., Alam, M.M., Siwar, C., and Mokthar, M. 2016. Measurement of Water Productivity in Seasonal Floodplain Beel Areas: Methodological Assessment. Asian Journal of Water, Environment and Pollution, Vol. 13(2), pp.1-14. [Online Link]

This is a pre-publication copy.

The published article is copyrighted by the publisher of the journal. 


\title{
Measurement of Water Productivity in Seasonal Floodplain Beel Area
}

\author{
Md. Istiaque Hossain ${ }^{1}$, Md. Mahmudul Alam ${ }^{* 2}$, Chamhuri Siwar $^{3}$, Mazlin Mokhtar $^{3}$ \\ 1. Department of Fisheries, Faculty of Agriculture, University of Rajshahi, Bangladesh \\ 2. School of Economics, Finance \& Banking, College of Business, Universiti Utara Malaysia, Malaysia \\ 3. Institute for Environment and Development, Universiti Kebangsaan Malaysia, Malaysia
}

\begin{abstract}
Water scarcity is becoming a central issue in agricultural activities around the world. As agriculture is one of the major consumers of freshwater, more yield or output using same or less amount of water has become the global interest. Therefore water productivity (WP) is also considered as an indicator of agricultural productivity. Several research works have been conducted on WP values of different yields, tools and technologies to improve WP. Most of the studies on water productivity considered the crop productivity using limited water resource and searched for better technologies for improving crop water productivity. Researchers also concentrated on improving irrigation efficiency or water use efficiency at field level for irrigation through water management and for yielding more crops. But there is a research gap in assessing values of water productivity in aquatic ecosystems especially floodplain areas. A floodplain area remains dry and flooded in two different seasons. Thus, a combined valuation of aquatic resources and rice production in two different seasons are very important to measure the efficient usages of the lands. So, this study deals with how to measure annual aggregate water productivity for dry season and flood season in a floodplain beel area.
\end{abstract}

Keywords: Floodplain; Beel; Water Productivity; Fish-Rice Culture

JEL Classification: C02; Q15; Q25

\section{Introduction}

Freshwater is a very important natural resource which is now scarce for its high demand in all sectors. Freshwater resources are facing increased competition among a multitude of users (Pimentel et al. 2004; Rijsberman 2006). In this condition of water scarcity, the limited and available water should be used more efficiently (Bessembinder et al. 2005). There are two key challenges to be faced by agriculture- food production needs to enhance for rapidly growing world population and this demand needs to be fulfilled under decreasing water resources. FAO's recent report (2003) on "World agriculture: towards 2015/30" projects that global food production needs to be increased by $60 \%$ to close nutrition gaps, cope with the population growth and accommodate changes in diets over the next three decades. Water withdrawals for agriculture are expected to increase by some $14 \%$ in that period, representing an annual growth rate of $0.6 \%$, from $1.9 \%$ in the period 1963-1999. Much of the increase will take place arable irrigated land and this forecasts to expand globally from some 2 million sq. $\mathrm{km}$ to 2.42 million sq. $\mathrm{km}$. In a group of 93 developing countries, water use efficiency in irrigation i.e. the ratio

\footnotetext{
* Corresponding author: Md. Mahmudul Alam, Email: rony000@gmail.com
} 
between water consumption by crops and the total amount of water withdrawal is expected to grow from an average $38 \%$ to $42 \%$. To meet up the food shortage, it is needed to produce more food from limited water (Dugan et al. 2006; Guerra et al. (1998) that is to increase water productivity (WP). Thus, to overcome food shortage for lack of water for irrigation, it is necessary to save water and to increase water productivity.

Floodplain lands appear as important aquatic ecosystem that supports wide range of biodiversity and provides indispensable benefits to the people. As freshwater resources are being pressurized with increased competition from multi sector uses, there has been growing recognition that improved management actions along with increased investment is needed to sustain these floodplain ecosystem and the benefits they provide. There is need to develop an innovative approach in managing these floodplain wetlands that will embrace the need for maximizing values of scarce resources, will ensure maintenance and sustainable development of this ecosystem and also will be able to promote future food security. The seasonal floodplains support a dense human population and are being utilized for crop production, fishing and for collecting other aquatic resources such as snails, aquatic plants etc. The floodplain lands remain unutilized or underutilized for a long period during flooding. But these water bodies can be used to raise food production for the ever increasing population by intervention of fish culture into existing farming system. The integration of rice and fish production is an efficient means for agricultural land use (Khoo \& Tan 1980).

A growing number of studies have demonstrated that substantial benefits can be obtained by combining intensive aquaculture with irrigated crop production, and thereby increasing water productivity (Dugan et al. 2006; D'Silva \& Maughan 1994; Bondari et al. 1983). A study conducted by the World Fish Centre (Dey \& Prein 2004) indicated that the adoption of integrated agriculture-aquaculture technology in Malawi has substantially increased WP and farm income (28\%) without any additional consumptive use of water.

It is anticipated that Asian countries especially Indian sub-continent will face freshwater scarcity in near future due to rapid population growth and negligence in appropriate water management. So to increase WP by using limited and scarce water resources should be prime concern for the scientists and for the policy makers. For the successful implementation of such approaches, information on values of resources and enhancement of these values are needed. In absence of such information, concerned authority or policy maker underestimate the contribution of these resources to productive water use and hence fails to take initiative to improve management actions to utilize these resources. Stakeholders also fail to fulfil their needs making proper uses of these water bodies. This leads to loss in terms of economic usage and hinders the achievement of effective help for benefiting from this underutilized water. Therefore assessment of water productivity of floodplain water body is essential for governmental purpose for the scopes prevailing in these water bodies to be utilized for better economic purposes and for producing more food from the same water resources.

\section{Measurements of Productivity}


Productivity is an important tool in evaluating and monitoring the performance of firms, industries, and countries. Improving productivity is essential in attaining global competitiveness with the end goal of achieving sustained economic growth. Productivity is defined as the relationship between output and factor inputs where output can be any goods or services produced and inputs refer to labor and/or capital. The most acceptable definition of productivity is that it is a quantitative relationship between output and input (Iyaniwura \& Osoba 1983; Antle \& Capalbo 1988). In any firm or industry, productivity is a concept that measures the efficiency with which inputs are transformed into valuable output in a production process. Productivity is seen as total output/total input which is identical to total results achieved/total resources consumed or effectiveness/efficiency (Amadi 1991).

In effect, productivity becomes the attainment of the highest level of performance with the lowest possible expenditure of resources. It represents the ratio of the quality and quantity of products in terms of the resources utilized. Olaoye (1985) observed that the concept "productivity" attains two dimensions: namely total factor productivity (TFP) and partial productivity (PFP). In economics, total-factor productivity (TFP) is a variable which accounts for effects in total output that is not only caused by physical inputs but other factors, such as natural factors, technology, skills and intuitions, etc. An important limitation of TFP is that it does not make adjustments with input "quality" changes. TFP is dimensionless and only changes if TFP has any meaning.

Alternatively PFP associates output in terms of marginal contribution of any single factor input. Dawe \& Dobermann (1999) define PFP as the average productivity of the single factor measured by grain output divided by the quantity of the factor applied. It can be measured for any factor of production such as labor, fertilizer, water, pesticide etc., assuming all other factors constant. Partial factor productivity is equally known as average product (Oyeranti 2000). Symbolically, if Y stands for output, and Fi for any individual factor, we have APF $=\mathrm{Y} / \mathrm{Fi}$ where $\mathrm{APF}$ is the average product. It only measures how the output per unit has changed over time, ignoring the contributions from other factors to the detriment of production process reality.

But the advantage of PFP over TFP is that it is easy to calculate. Productivity can be measured by partial and total factor productivity (TFP). Partial measures are the amount of output per unit of a particular input. Commonly used partial measures are yield (output per unit of land), and labour productivity (output per economically active person or per agricultural person-hour) (Block 1994). According to Barker et al. (2003) PFP measures return to scarce or limited resources. Where land is the scarce resource, the economic benefits are obtained by increasing output per unit of land area. Then, technologies are improved and implemented that will increase yield per hectare (e.g. high-yielding varieties and fertilizer). As water is considered as scarce resource for agricultural production now a days, there is rising interest in measuring raising WP which is the output against water input, a classical example of PFP.

\section{Measurements of Water Productivity}


Water productivity broadly denotes the outputs (goods and services) derived from a unit volume of water. Generally productivity implies efficient water use that can be increased by either producing more output per unit of water used or by reducing water losses or by the combination of both. Therefore, the concept of water productivity in agricultural production systems has focused on 'producing more food with the same water resources' or 'producing the same amount of food with less water resources'.

According to Molden (1997) water productivity is the physical mass of production or the economic value of production measured against gross inflows, net inflows, depleted water, process depleted water or available water. At basin level, water productivity spans multiple uses and sectors: crop production, livestock production, tree production, fisheries production, ecosystem services, domestic, industrial, power generation, tourism and recreational. Molden and Saktivadivel (1999) define WP as the value or weight obtained per unit of water used or consumed. Sharma (2006) also defines productivity of water as the benefits derived from use of water and is most often given in terms of mass of produce, or its monetary value, per unit of water. According to him, water productivity is dependent on several factors, including crop genetic material, water management practices and the economic and policy incentives to produce. Integrated Water Management Institute (IWMI) researchers have been of the view that this definition is scale dependent. For a farmer, it means getting more crops per drop of irrigation water. But at a regional basin or a country level water productivity means getting more value per unit of water resources used. It can be further defined in several ways according to the purpose, scale and field of analysis (Bastiaanssen et al. 2003; Molden et al. 2001). As shown in Table 1, farmers, plant physiologists, engineers and agronomists have different meanings about the term of the productivity of water equation. It is a multidimensional measurement and that it is not easy to reach a consensus but it may be logical to consider each and every component of the benefits and water use in the process.

Table 1: Examples of definitions of productivity of water by different stakeholders

\begin{tabular}{llll}
\hline Stakeholder & Definition & Scale & Target \\
\hline Plant physiologist & Dry matter /transpiration & Plant & $\begin{array}{l}\text { Utilize light and Water } \\
\text { resources }\end{array}$ \\
Agronomist & Yield / evapotranspiration Field & Sufficient food \\
Farmer & Yield / irrigation & Field & Maximize income \\
Irrigation engineer & Yield / canal water supply Irrigation scheme & Proper water allocation \\
Policy maker & \$ / available water & River basin & Maximize profits \\
\hline
\end{tabular}

Source: Adapted from Bastiaanssen et al. 2003

Plant breeders and agronomic scientists look to obtain more kg of dry matter or grain per unit amount of transpiration or evapotranspiration. The definition of water productivity, therefore, brings both the plant breeders and the agronomists to a common communication platform, and can be used as a standard unit of evaluation. Low values of water productivity in terms of $\mathrm{kg}$ of grain per unit amount of evapotranspiration 
suggest an agronomist to reduce soil evaporation by improving agronomic practices such as mulching.

Similarly low crop yields under high irrigations at field scale indicate poor field irrigation management or the status of other management factors such as nutrient, pest and disease control. For irrigation engineers, canal water supply is a key factor. They will evaluate their own water productivity based on the crop yields in relation to the canal water supplies. Water productivity can also be defined in economic terms: monetary value (\$) / amount of water used. These economic values are useful to compare different crops and to evaluate the net benefits derived from a particular crop. The economic definition of water productivity also provides a better basis for policy makers to decide on agricultural and non-agricultural utilization of water such as for industries, bird habitats and tourism.

Molden and Sakthivadive (1999) demonstrated a methodology to account for the use and productivity of water resources. This water accounting methodology presents useful information for water resource stakeholders and decision makers to better understand the present use of water and to formulate actions for improvements in integrated water resources management systems. Based on a water balance approach, it classifies outflows from a water balance domain into various categories to provide information on the quantity of water depleted by various uses, and the amount available for further use. The methodology is applicable to different levels of analysis ranging from a micro level such as a household, to a macro level such as a complete water basin.

Renwick (2001) measured the value of water in irrigated agricultural and reservoir fisheries using economic valuation (TEV) framework. The total economic valuation (TEV) framework provides a systematic approach for assessing the combined economic values of all the goods and services produced by a resource-based system (Pearce 1993; Randall 1991). This report took the first step in the TEV approach by focusing on economic valuation of two important uses of water irrigated paddy production and reservoir fisheries. To better understand the potential financial and economic gains obtained from improvements in system performance, a producer-level profit maximization model was utilized to estimate the value of water in paddy cultivation under current and targeted cropping intensities. From a production theory perspective, irrigation of water is an intermediate good, an input used to produce a final product. The value of an intermediate good is defined as the net economic contribution of that good to the value of the final output. Under this approach, all costs of production, except water, are subtracted from the value of production. This remaining (or residual) value provides an estimate of the value of irrigation. In estimating the economic costs, particular attention was given to estimate all input costs including noncash costs such as land, family labor, returns to management, and depreciation for machinery and equipment. Economic returns to water measure the contribution of water, as a production input, to the total value of the output. Economic returns provide a measure of the value of water in its current use.

The term TEV stands for both use values and non-use values. It is mostly of abstract or theoretical values except for the direct extractive values which are used as direct market values. Spatial and chronological variation, accessibility to users and the 
relative values of the stakeholder groups are calculated depending upon various factors. Bateman et al. (2002) stated that use values relate to actual use, possible use or planned use of the good in question. These are divided into direct uses, indirect uses and optional uses. Direct uses can be either extractive or non-extractive.

Molden et al. (2003) provided a framework to show the interrelationship of the work of various disciplines. They suggested the following strategies to increase water productivity at different levels:

1) Increasing the productivity per unit of water consumed

i) Improved water management- better irrigation scheduling to avoid stress to plants, increasing reliability of water supplies to synergise other production inputs.

ii) Improving non-water inputs- better agronomic management, resource conservation technologies.

2. Reducing non-beneficial depletion

i) Cutting non-beneficial evaporation- fallow lands, free water surfaces, weeds, and low-value vegetation.

ii) Reducing water flows to sinks- irrecoverable deep percolation and surface runoff.

iii) Minimizing Stalinization of return flows: applying just the right amount of water to saline soils or soils with saline aquifers and shunting polluted water directly to appropriate sinks.

3. Reallocating water among uses

i) Reallocating water from lower-value to higher value uses

4. Tapping uncommitted outflows

i) Improving management of existing facilities- obtain more beneficial use from existing supplies by policy, design, management and institutional interventions.

ii) Reusing return flows- to increase irrigated area.

iii) Adding storage facilities- to meet the peak requirements during scarcity periods through reservoirs, groundwater recharge, small tanks and ponds at farmers' fields.

iv) Minimizing Stalinization of return flows: applying just the right amount of water to saline soils or soils with saline aquifers and shunting polluted water directly to appropriate sinks.

Cai and Rosegrant (2003) analyzed water productivity at the global and regional levels through a holistic modeling framework, IMPACT-WATER, an integrated water and food model developed at the International Food Policy Research Institute (IFPRI). Scenario analysis was undertaken to explore the impact of technology and management improvement and investment on water productivity and to search for potentials in improving food security through enhancing water productivity. It was found that the water productivity of rice ranged from 0.15 to $0.60 \mathrm{~kg} \mathrm{~m}^{-3}$, while that of other cereals ranged from 0.2 to $2.4 \mathrm{~kg} \mathrm{~m}^{-3}$ in 1995 . During the years starting from 1995 to 2025 , water productivity will be on rise. The global average water productivity of rice and other cereals will increase from $0.39 \mathrm{~kg} \mathrm{~m}^{-3}$ to $0.52 \mathrm{~kg} \mathrm{~m}^{-3}$ and from $0.67 \mathrm{~kg} \mathrm{~m}^{-3}$ to 1.01 $\mathrm{kg} \mathrm{m}^{-3}$, respectively. Both - the increase in crop yield and improvement in basin 
efficiency will contribute to the increase in water productivity, but the major contribution will come from increase in the crop yield.

Bowen (2003) used SUBSTOR-Potato model as a tool for analyzing the impact of weather variability on potato yields and water productivity under different management practices. This model simulates, on a daily basis, the accumulation and partitioning of biomass and the phonological development of a potato crop as influenced by temperature, photoperiod, intercepted radiation and soil water and nitrogen $(\mathrm{N})$ supply. The model is thought to be especially valuable for studies of the interaction of water and $\mathrm{N}$ supply. SUBSTOR has been tested in various environments and has generally performed well when simulated data have been compared with measured data (Griffin et al. 1995; Mahdian \& Gallichand 1995; Ritchie et al. 1995; Travasso et al. 1997; Bowen et al. 1999). It is also calibrated and tested across a wide range of environments and management systems in the Andes and more recently in the IndoGangetic plains of India. A comparison of simulated and observed tuber yields is obtained from field studies in the Andes. This limited testing shows that the model realistically simulated fresh tuber yields that ranged from $4 \mathrm{t} \mathrm{ha}^{-1}$ to $56 \mathrm{t} \mathrm{ha}^{-1}$ due to differences in weather, soils, cultivars and management.

Senzanje et al. (2005) presented the results of a study to quantify field water productivity (WP) at ARDA Middle Save Estates in the Save Catchment in Zimbabwe over a 5-year period (1998-2002) for winter wheat and cotton. The water productivity was quantified using a single indicator, the productivity of irrigation water $\left(\mathrm{kg} \mathrm{m}^{-3}\right)$ at field level. The field-scale WP indicator was determined from crop output and total water supplied (irrigation and effective precipitation) to the field as selected because it is more appropriate and easy to interpret by management. The total amount of water applied during the growth period was the sum of the amount of water pumped (derived from pumping records taking into account the growth period of the crop) and the contribution due to natural rainfall. The mean WP of winter wheat ranged from $0.49 \mathrm{~kg}$ $\mathrm{m}^{-3}$ to $0.60 \mathrm{~kg} \mathrm{~m}^{-3}$ with an insignificant downward trend over the 5-year period. For cotton, the WP averaged $0.09 \mathrm{~kg} \mathrm{~m}^{-3}$ to $0.33 \mathrm{~kg} \mathrm{~m}^{-3}$ with a downward but significant trend $(\mathrm{p}<0.034)$ over the 5-year assessment period. The WP levels of both crops are lower than international averages for comparable situations indicating the need for Middle Save Estates to put into practice measures to raise WP levels. For the cotton crop, total water applied encompassed both effective precipitation and the water pumped, and for the winter wheat this refer to the water pumped since rainfall is an insignificant contributor.

Henry et al. (2006) set an experiment on the maize crop at eight different seasonal water application depths: 400, 490, 500, 510, 590, 600, 610 and $700 \mathrm{~mm}$, in two of the three fields, and at five water application depths: 400, 590, 600, 610 and $700 \mathrm{~mm}$ in the third field. The variation in seasonal water application depth was achieved by skipping the weekly irrigation once after every other irrigation at some predefined stages of the crop growth. CWP were computed in terms of crop water use, water applied, and economic returns. The CWP in terms of crop water use was found to range from 0.40 to $0.70 \mathrm{~kg} \mathrm{~m}-3$ among the treatments in the three fields, while the CWP in terms of water applied varied from 0.40 to $0.55 \mathrm{~kg} \mathrm{~m}-3$. The amount of irrigation water applied at the different growth stages of the crop and the growth stage response to 
moisture stress influenced the status of CWP. CWP was maximized by withholding irrigation every other week at vegetative and grain filling and observing weekly irrigation at flowering growth stage. However, the grain yield loss associated with irrigation schedule was about 20-28\%. Convincing farmers to accept a trade-off between maximizing CWP at the expense of yield reduction may remain one of the greatest challenges that will be faced by irrigation water management stakeholders.

Sharma (2006) discussed water accounting framework for improving water productivity. He stated that the water accounting procedure classifies the inflow and outflow components into various water accounting categories and are explained below:

- Process depletion: by crops, cities, industries

- Non-process but beneficial depletion: evaporation by trees, wetlands, fisheries

- Evaporative depletion of low or negative benefit: evaporation from fallow lands, waterlogged areas etc.

- Flows directed by irrigation into sinks: to sea, inland water bodies that do not add value but are considered as water depleted by irrigation

- Uncommitted flows: utilizable within the irrigation system or elsewhere

- Committed flows to meet environmental needs and traditional rights of downstream users.

- Committed flows to meet environmental needs and traditional rights of downstream users.

Bouman (2007) revealed that a systematic framework built on generic principles for the analysis of WP can help to identify interventions that can contribute to the dual goal of increasing food production and saving water. He proposed a conceptual framework with four principles that can be applied at different scales: (1) increase transpiration crop water productivity, (2) increase the storage size for water in time or space, (3) increase the proportion of non-irrigation water inflows to the storage pool, and (4) decrease the non-transpiration water outflows of the storage pool. The framework is limited to a biophysical analysis of agricultural crops (quantitative yield) and does not include the quality or economic value of crop produce. It is mostly relevant for bulk food crops, such as cereals and tubers, and animal fodder crops, but probably less so for vegetables and fruits. Practical interventions that are suggested through application of the framework should be economically evaluated before implementation. This becomes especially relevant at spatial scales beyond the field where different crops with different economic values may be grown and allocation of water among crop types becomes an issue. Also, at larger spatial scales such as the landscape, the framework is limited to situations where crops are the only or dominant user of water. In landscapes with multiple users of water (e.g., domestic users, industry, livestock, nature), allocation of water among these users becomes more of an issue. In such situations, the water accounting framework as developed by Molden et al. (2003) is a more appropriate tool for analysis of water productivity than this framework.

Liu et al. (2008) revealed a comparison between simulated yields and FAO statistical yields in 124 countries and this comparison shows a good agreement. The GEPIC model was applied to simulate crop yield and crop water productivity (CWP) for maize at a spatial resolution of 30 arc-minutes on a global scale The simulated CWP 
values are mainly in line with the measured values reported in literature. The crop yield and CWP were simulated with the assumption of sufficient water and fertilizer supply, holding other factors unchanged. The simulation results show that many countries have the potentials in achieving high maize yields and CWP. More than $80 \%$ of African countries have the potential to double their CWP. This reflects the current poor water and fertilizer management there.

Ali and Talukder (2008) argued that a single approach will not be able to tackle the forthcoming challenge of producing more food and fiber with limited or even reduced available water. Combining biological water-saving measures with engineering solutions (water saving irrigation method, deficit irrigation, proper deficit sequencing, modernization of irrigation system, etc.), and agronomic and soil manipulation (seed priming, seedling age manipulation, direct- or wet-seeded rice, proper crop choice, integrating agriculture and aquaculture, increasing soil fertility, addition of organic matter, tillage and soil mulching, etc.) may solve the problem to a certain extent. They emphasised on new scientific information to improve the economic gains of WP because they think that future improvements in WP seem to be limited by economic rather than a lack of technological means.

Rashidi and Gholami (2008) reviewed the measured crop water productivity values for irrigated tomato, potato, melon, watermelon and cantaloupe in Iran based on of 39 literature sources with results of experiments not older than 20 years. The range of CWP is very large (Tomato, 2.58-11.88 $\mathrm{kg} \mathrm{m}^{-3}$; potato, $1.92-5.25 \mathrm{~kg} \mathrm{~m}^{-3}$; melon, 2.46$8.49 \mathrm{~kg} \mathrm{~m}^{-3}$; watermelon, $2.70-14.33 \mathrm{~kg} \mathrm{~m}^{-3}$ \& cantaloupe, $4.18-8.65 \mathrm{~kg} \mathrm{~m}^{-3}$ ) which offers tremendous opportunities for maintaining or increasing agricultural production with 20-40\% less water resources. The variability of CWP can be ascribed to climate and irrigation water management among others. The vapor pressure deficit is inversely related to CWP. Vapor pressure deficit decreases with latitude and thus favorable areas for water wise irrigated agriculture are located at the higher latitudes.

Most of the literatures discussed water saving measures that refer to technologies that lead to reduction in the water supply to the field of interest. But water saving does not always lead to higher water productivity. Because, functions relating output to input (e.g. water,) are nearly always concave because the use of higher levels of input is eventually subject to diminishing returns. When such a function is purely concave, partial factor productivity is maximized by using as little of the input as possible, even when it results in large declines in output (because, as input use declines towards zero, productivity increases towards infinity). Thus, the appropriate goal should be to optimize WP, not maximize it (Barker et al. 2003). So there remains a scope for increasing WP with respect to water volume. Therefore management of water should aim at filling the gap between the potential and actual water productivity. It also became obvious that WP studies have mostly dealt with improving crop water productivity and substantial progress has already been made in developing water-saving technologies to increase crop WP. But the researchers overlooked the utilization of existing water resources for improving water productivity of aquatic ecosystem. It is needed to know the WP values and the prevailing scopes to improve WP to produce more food from available water resources. In flooded wetlands where there remains water use contest between agriculture and aquaculture, an integrated approach is obligatory in 
establishing WP enhancing management approaches. If beneficiaries can be well informed about the WP values, integrated water resource management can be effective in enhancing water productivity and also in ensuring conservation and propagation of water resources.

\section{Measurements of Water Productivity in Floodplain Beel Area}

Floodplain is a low lying flat land which is adjacent to a stream or river that experiences occasional or periodic flooding (Powell 2009). It is a dry area susceptible to being inundated by water from any natural resource. Some places, like Bangladesh, farmlands that become flooded (over 1 meter depth) during wet season are known as floodplain (Hossain et al. 2013, 2015). Beel is a very common form of floodplain area in the Ganga-Brahmaputra floodplains of the states of West Bengal, and Assam in India and in Bangladesh. It is formed by inundation of low lying lands during flooding, where some water gets trapped even after flood waters recede back from the floodplains. It also may be caused by rain water during monsoon season. There are two types of beels viz., the seasonal beels which dry-up annually and the perennial beels which retain water round the year. Beels may be formed from big river when the mainstream of the river changes the direction leaving a remnant. Again this can be formed as a result of silt deposition in the river bed which makes the river flow with two parallel streams leaving a land in between. The land between a pair of parallel rivers then forms a ditch or depression which is converted to beel during flooding (Alam \& Hossain 2007). Beels are more potential water resources among the vast inland fishery. Soil and water of floodplains (beels) are very productive and are inhabited by distinct flora and fauna. It is a very good natural habitat of large and small indigenous fishes of different food habits. Many of fish and prawn species can be multiplied in number in beels. Many other fish and prawn species move into the inundated areas of beel from adjacent rivers and canals to feed and grow during monsoon.

This study discusses both physical (yield of outputs against volume of water) and combined physical and economic water productivity (value of outputs against volume of water) for measuring WP in floodplain water bodies. Both wet and dry seasons are needed for assessing water productivity of the seasonal floodplain lands. This study measures water productivity during wet season by introducing fish culture and during dry season by valuating agriculture.

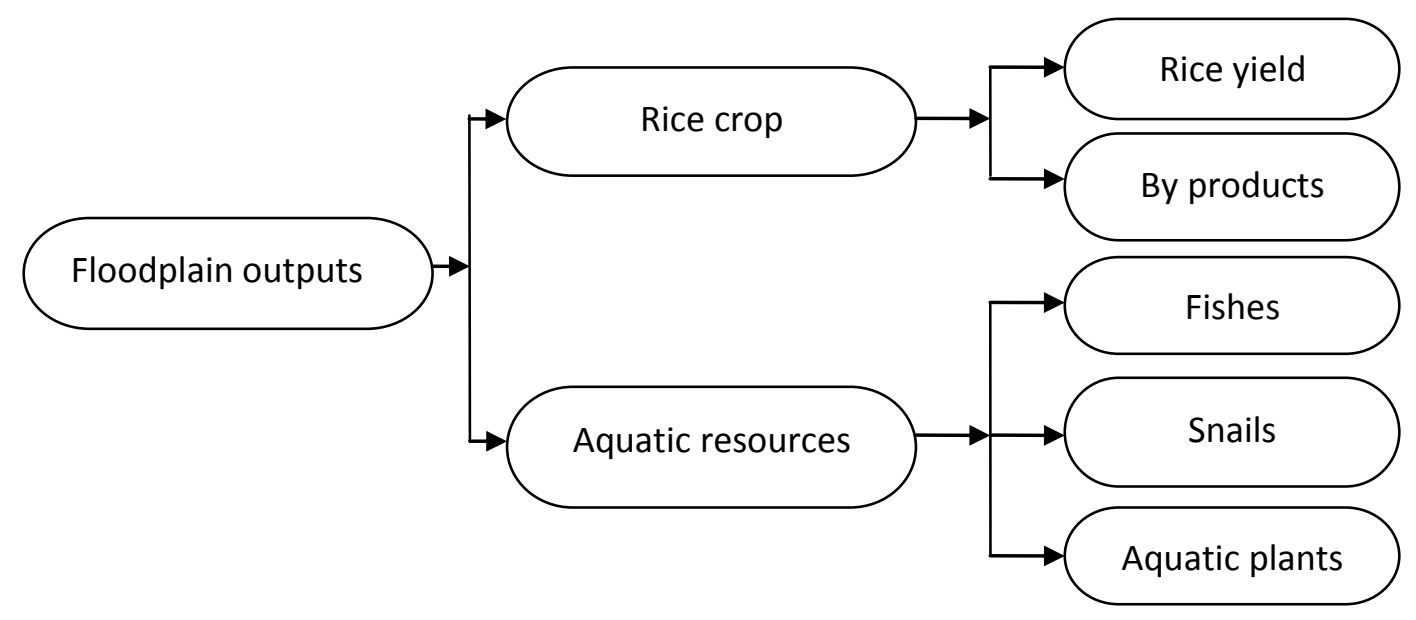


Figure 1: Rice and aquatic resources from seasonal floodplain beel

Water productivity was measured as partial factor productivity i.e. productivity of unit of water use with aquatic and terrestrial environment framework in wet season and with water accounting framework in dry season. The outputs considered here are the output products obtained from both extractive and non extractive uses of water. When water is used for production purpose by moving from main source that refers to extractive use i.e., use of water for agricultural crops, whereas it is used without moving from main source that refers to non-extractive use e.g. water is used for fish, snails and aquatic plants.

This framework differentiates the natural environments into two discrete ecological regimes - aquatic and terrestrial, based on the presence or absence of standing or permanent water in the land area. In aquatic environment, there is presence and abundance of standing or perpetually flowing water in its natural state. Examples of these natural water resources are lakes, rivers, streams, ponds, wetlands, marshes, and the sea. While the terrestrial environment is the relatively dry land areas, which include pasture, rangeland, forest and agricultural lands. The aquatic and terrestrial environments can boast parallel role when both are used as production media in the generation of benefits and values even if dissimilar in ecological composition. Land resources are used for agriculture produce crops and livestock, while water resources are used for aquaculture produce fish and fishery products and aquatic plants and foodcrops.

\subsection{Water Productivity for Rice Cultivation}

Water use efficiency (WUE), irrigation efficiency (IE), and WP have been defined according to use, field of research and stakeholder. Crop physiologists defined WUE as carbon assimilated and crop yield per unit of transpiration (Viets 1962), and then later as the amount of produce (biomass or marketable yield) per unit of evapotranspiration (ET). Taking into account that photosynthesis (and thus dry matter yield) and transpiration are related through the diffusion process of $\mathrm{CO}_{2}$ and $\mathrm{H}_{2} \mathrm{O}$, the efficiency of crop water use has been defined as,

$$
\text { Water efficeincy }=\frac{\text { Dry metter growth rate }}{\text { Transpiration rate }}=\frac{\mathrm{Y}\left(\mathrm{kg}^{-1} \mathrm{~d}^{-1}\right)}{\mathrm{T}\left(\mathrm{mm} \mathrm{d}^{-1}\right)}
$$

Irrigation specialists have used the term WUE to describe how effectively water is delivered to crop sand to indicate the amount of water wasted. But this concept provides only a partial view because it does not indicate the benefits produced, nor does it specify that water lost by irrigation is often reused by other uses (Seckler et al. 2003). In daily irrigation practices, 'water productivity' WP is a more applicable term in equation 1, as it assimilates the rate of dry matter yield and transpiration over time, i.e. denoted as $\mathrm{Y}$ and $\mathrm{T}$ respectively. 


$$
\mathrm{WP}_{\mathrm{T}}=\frac{\mathrm{Y}\left(\mathrm{kg} \mathrm{ha}^{-1}\right)}{\mathrm{T}(\mathrm{mm})} \rightarrow \frac{\mathrm{Y}\left(\mathrm{kg} \mathrm{ha}^{-1}\right)}{\mathrm{T}\left(\mathrm{m}^{3} \mathrm{ha}^{-1}\right)} \rightarrow \mathrm{kg} \mathrm{m}^{-3}
$$

Where, $1 \mathrm{~mm}$ is equivalent to $10 \mathrm{~m}^{3} \mathrm{ha}^{-1}$. When applying irrigation at field scale, it is generally difficult to distinguish plant transpiration $\mathrm{T}(\mathrm{mm})$ from soil evaporation $\mathrm{E}$ $(\mathrm{mm})$. Hence, instead of $\mathrm{WP}_{\mathrm{T}}, \mathrm{WP}_{\mathrm{ET}}$ may be used (Molden 1997; Molden et al. 2001; Droogers \& Bastiaanssen 2002; Kijne et al. 2003):

$$
\mathrm{WP}_{\mathrm{ET}}=\frac{\mathrm{Y}\left(\mathrm{kg} \mathrm{ha}^{-1}\right)}{\mathrm{ET}\left(\mathrm{m}^{3} \mathrm{ha}^{-1}\right)} \rightarrow \mathrm{kg} \mathrm{m}^{-3}
$$

Where, ET is the evapotranspiration of 'crop + soil'. Total dry matter yield Y may also be transformed into marketable yield, i.e. $\mathrm{Y}_{\mathrm{M}}$. If the amount of irrigation and precipitation water is considered as 'water use of the crop' then $\mathrm{WP}_{\mathrm{I}+\mathrm{P}}$ may be used,

$$
\mathrm{WP}_{\mathrm{I}+\mathrm{P}}=\frac{\mathrm{Y}\left(\mathrm{kg} \mathrm{ha}^{-1}\right)}{[\mathrm{I}+\mathrm{P}]\left(\mathrm{m}^{3} \mathrm{ha}^{-1}\right)} \rightarrow \mathrm{kg} \mathrm{m}^{-3}
$$

Where, I stands for amount of seasonal irrigation and $\mathrm{P}$ for the seasonal precipitation. Where ER (effective rainfall) is very negligible resulting in very low precipitation like arid regions or for dry season crop, $\mathrm{WP}_{\mathrm{I}+\mathrm{P}}$ may be converted to $\mathrm{WP}_{\mathrm{I}}$ (Vazifedoust et al. 2008)

$$
\mathrm{WP}_{\mathrm{I}}=\frac{\mathrm{Y}\left(\mathrm{kg} \mathrm{ha}^{-1}\right)}{\mathrm{I}\left(\mathrm{m}^{3} \mathrm{ha}^{-1}\right)} \rightarrow \mathrm{kg} \mathrm{m}^{-3}
$$

At the field scale, classical WP indicator is crop output and total water supplied (irrigation and effective precipitation) to the field because it is more appropriate and easy to interpret by management (Senzanje et al. 2005). As the farmer is mainly interested in the economic yield of the crop, WP may be expressed in terms of money as,

$$
\mathrm{WP}_{\$}=\frac{\left(\$ \mathrm{~kg}^{-1}\right)\left(\mathrm{kg} \mathrm{ha}^{-1}\right)}{\mathrm{ET}\left(\mathrm{m}^{3} \mathrm{ha}^{-1}\right)} \rightarrow \$ \mathrm{~m}^{-3}
$$

So water productivity measurement is straight forward in crop per drop analysis, which analyzes output (benefit quantity or value of product), over quantity of input (volume of depleted water). So in dry season, productivity from rice cultivation is expressed by rice yield. The equation 7 measures the water productivity of crops in physical terms as,

$$
\mathrm{WP}_{\mathrm{y}}=\frac{Q_{y}}{W C}
$$

Where,

$\mathrm{WP}_{\mathrm{y}}=$ water productivity in terms of crops yield

$Q_{y} \quad=$ yield of crop as physical units 
WC = consumption of depleted water, expressed in cubic meters

That is, physical productivity is the quantity (Qy) of product per unit quantity of depleted water (Hossain et al. 2013). The equation 8 measures the water productivity in terms of value as:

$$
W P_{y}=\frac{Q_{v}}{W C}
$$

Where,

$\mathrm{WP}_{\mathrm{y}}=$ water productivity in monetary terms of crop

$Q_{V} \quad=$ gross/ net value of yield output in monetary terms

$\mathrm{WC}=$ consumption of depleted water, expressed in cubic meters

Again, it is evident that equation 8 is the more suitable measure in case of multiproduct outputs. The value of output, $Q_{V}$, is the summation of values of different products resulting from application of unit amount of water.

The water productivity of rice crop in physical terms as,

$$
\begin{aligned}
& \mathrm{WP}_{\mathrm{y}}\left(\mathrm{Kg} \mathrm{m}^{-3}\right)=\frac{Q_{y}(K g)}{W C\left(m^{3}\right)} \\
& \mathrm{WC}\left(\mathrm{m}^{3}\right)=\mathrm{BWC}+\mathrm{NBWC}
\end{aligned}
$$

Where,

$\mathrm{WP}_{\mathrm{y}}=$ water productivity in physical units in terms of rice yield

$Q_{y} \quad=$ yield of rice crop, usually expressed in $\mathrm{Kg}$

$\mathrm{WC}=$ consumption of depleted water, expressed in cubic meters

$\mathrm{BWC}=$ beneficial water consumption in cubic meter

$\mathrm{NBWC}=$ Non-beneficial water consumption in cubic meter

The water productivity of rice crop in terms of value:

$$
\mathrm{WP}_{\mathrm{y}}\left(\mathrm{TK} \mathrm{m}^{-3}\right)=\frac{\mathrm{Q}_{\mathrm{v} 1}(\mathrm{TK})+\mathrm{Q}_{\mathrm{v} 2}(T K)}{\mathrm{WC}\left(\mathrm{m}^{3}\right)}
$$

Where,

$\mathrm{WP}_{\mathrm{y}}=$ water productivity in terms of monetary valued

$Q_{V 1} \quad=$ value of net return by rice yield

$Q_{V 2} \quad=$ value of net return of by product

WC = consumption or depleted water

That is, water productivity is the value of product per unit quantity of depleted water. The same equation is also applicable for measuring WP of by product of crop. It is evident that equation 11 is the more suitable measure in case of multi-product outputs. The value of output, $Q_{V}$, is the summation of values of different products resulting from application of water.

\subsection{Water Productivity for Fisheries and Other Aquatic Resources}


Under aquatic and terrestrial environment framework, the measurement of productivity means that water in the natural setting is a resource similar to land resource, and can be used as habitat or biophysical medium in the production of values and benefits. Water productivity measures are expressed by the equations given below. The equation 12 measures water productivity in pure physical terms as

$$
W P_{p}=\frac{Q_{p}}{A_{w r}}
$$

Where,

$W P_{p} \quad=$ Water productivity in terms of fisheries products.

$Q_{p} \quad=$ Net production of aquatic/fisheries products as physical units

$A_{w r} \quad=$ Surface area of water body in hectare

Here physical productivity is the quantity of net fisheries product that is, $Q_{p}$ is Wild fish (naturally occurring fishes) or culturable fish (fish for culture) or snails or aquatic plants per unit surface area of seasonal floodplain beels used for production. But for net production of culturable fish $\mathrm{Q}_{\mathrm{p}}$ is gross fish production minus stock of fish fingerlings per unit surface area of water body. The equation 13 measures the water productivity in value terms as

$$
\mathrm{WP}_{\mathrm{p}}=\frac{\mathrm{Q}_{\mathrm{v}}}{A_{w r}}
$$

Where,

$\mathrm{WP}_{\mathrm{p}}=$ water productivity in terms of fisheries products

$\mathrm{Q}_{\mathrm{v}} \quad=$ value of net productions in monetary terms

$\mathrm{A}_{\mathrm{wr}} \quad=$ surface area of water body in hectare.

Equation 13 is suitable for multi-product outputs. The value of output $\left(\mathrm{Q}_{\mathrm{v}}\right)$ here can be taken as the summation of the values of the different products derived from the multiple uses of the seasonal floodplain beels. It is to be noted that in this analytical framework, seasonal floodplain beels are treated as land resources, whose productivities are measured in terms of surface area used for agricultural production.

The following equations were followed by early researchers to measure the water productivity of living aquatic resources (fish, snails and aquatic plants) in physical terms,

$$
\begin{aligned}
\mathrm{WP}_{1}\left(\mathrm{Kg} \mathrm{ha}^{-1}\right) & =\frac{Q_{1 o}(K g)-Q_{1 i}(K g)}{A_{w r}(h a)} \\
\mathrm{WP}_{2}\left(\mathrm{Kg} \mathrm{ha}^{-1}\right) & =\frac{Q_{2}(K g)}{A_{w r}(h a)} \\
\mathrm{WP}_{3}\left(\mathrm{Kg} \mathrm{ha}^{-1}\right) & =\frac{Q_{3}(K g)}{A_{w r}(h a)}
\end{aligned}
$$

Where,

$\mathrm{WP}_{1}\left(\mathrm{Kg} \mathrm{ha}^{-1}\right)=$ water productivity of fish (wild or culturable) in terms of $\mathrm{Kg}$ $\mathrm{WP}_{2}\left(\mathrm{Kg} \mathrm{ha}^{-1}\right)=$ water productivity of snails in terms of $\mathrm{Kg}$ 
$\mathrm{WP}_{3}\left(\mathrm{Kg} \mathrm{ha}^{-1}\right)=$ water productivity of aquatic plants in terms of $\mathrm{Kg}$

$Q_{p 1 o}(K g) \quad=$ gross output of fish, usually expressed in $\mathrm{Kg}$

$Q_{p 1 i}(K g) \quad=$ gross input of fish fingerlings, usually expressed in $\mathrm{Kg}$

$\mathrm{Q}_{2}(\mathrm{Kg}) \quad=$ net output of snails, usually expressed in $\mathrm{Kg}$

$\mathrm{Q}_{3}(\mathrm{Kg}) \quad=$ net output of aquatic plants, usually expressed in $\mathrm{Kg}$

$A_{w r}(h a) \quad=$ per hectare area of seasonal floodplain beels

The following equations measure the aggregate water productivity of living aquatic resources (fish, snails and aquatic plants) in physical terms,

$$
W P_{p}\left(K g \mathrm{ha}^{-1}\right)=\frac{Q_{1}(K g)+Q_{2}(K g)+Q_{3}(K g)+Q_{4}(K g)}{\mathrm{A}_{\mathrm{wr}}(\text { ha })}
$$

Where,

$\mathrm{WP}_{\mathrm{p}}=$ per hectare $\mathrm{WP}$ by living aquatic resources in terms of $\mathrm{Kg}$

$\mathrm{Q}_{1} \quad=$ net output of culturable fish, usually expressed in terms of $\mathrm{Kg}$

$\mathrm{Q}_{2} \quad=$ net output of wild fish, usually expressed in terms of $\mathrm{Kg}$

$\mathrm{Q}_{3} \quad=$ net output of snails, usually expressed in terms of $\mathrm{Kg}$

$\mathrm{Q}_{4} \quad=$ net output of aquatic plants, usually expressed in terms of $\mathrm{Kg}$

$A_{w r}(h a)=$ per hectare area of seasonal floodplain beels

The following equations measure the water productivity of living aquatic resources (fish, snails and aquatic plants) in values,

$$
\begin{aligned}
& \mathrm{WP}_{\mathrm{p}}\left(\$ \mathrm{ha}^{-1}\right)=\frac{Q_{v 1 o}(\$)-Q_{v 1 i}(\$)}{A_{w r}(h a)} \\
& \mathrm{WP}_{\mathrm{p}}\left(\$ \mathrm{ha}^{-1}\right)=\frac{Q_{v 2}(\$)}{A_{w r}(h a)} \\
& \mathrm{WP}_{\mathrm{P}}\left(\$ \mathrm{ha}^{-1}\right)=\frac{Q_{v 3}(\$)}{A_{w r}(h a)} \\
& \mathrm{WP}_{\mathrm{P}}\left(\$ \mathrm{ha}^{-1}\right)=\frac{Q_{v 4}(\$)}{A_{w r}(h a)}
\end{aligned}
$$

Where,

$\mathrm{WP}_{\mathrm{P}}\left(\$ \mathrm{ha}^{-1}\right)=$ water productivity by fisheries products per $\left(\mathrm{ha}^{-1}\right)$ in monetary value

$Q_{1 v}=Q_{v 10}-Q_{v 1 i}=$ net return of cultivable fishes usually expressed in monetary value

$Q_{2 v}(\$)=$ net return of wild fishes, usually expressed in monetary value

$Q_{3 v}(\$)=$ net output of snails, usually expressed in monetary value

$Q_{3 v}(\$)=$ net output of aquatic plants, usually expressed in monetary value

$A_{w r}(h a)=$ per hectare area of seasonal floodplain beels

As physical productivity varies among different living aquatic resources, the productivity in terms of monetary value is the only proper measurement to calculate the aggregate water productivity. The following equations measure the aggregate water 
productivity of living aquatic resources (fish, snails and aquatic plants) in terms of values,

$$
W P_{p}\left(\$ \mathrm{ha}^{-1}\right)=\frac{Q_{v 1}(\$)+Q_{v 2}(\$)+Q_{v 3}(\$)+Q_{v 4}(\$)}{\mathrm{A}_{\mathrm{wr}}(\mathrm{ha})}
$$

Where,

$\mathrm{WP}_{\mathrm{p}}=$ per hectare WP by living aquatic resources is $\left(\$ \mathrm{ha}^{-1}\right)$

$\mathrm{Qv}_{1} \quad=$ net return of culturable fish

$\mathrm{Qv}_{2}=$ net return of wild fish

$\mathrm{Qv}_{3}=$ net return of snails

$\mathrm{Qv}_{4} \quad=$ net return of aquatic plants

$\mathrm{A}_{\mathrm{WR}}=$ per hectare area of seasonal floodplain beels

That is, productivity is the value of fisheries products per unit surface area of the seasonal floodplain beels used for production. It is evident that equation 22 is suitable for multi-product outputs. The value of output $\left(\mathrm{Q}_{\mathrm{V}}\right)$ here can be taken as the summation of the values of the different products derived from the multiple uses of the seasonal floodplain beels.

\subsection{Aggregate Annual Water Productivity}

Measuring the aggregate value of the productivity among two seasons is important because, availability of water in one season is also highly correlated with the productivity in another season. Longer water stay in beel area for fish culture made the irrigation water requirement less and lowered land preparation cost.

However, the aggregate measurement of water productivity around the year is complex due to the differences in measurement units. For the dry season, the productivity of water is generally measured in terms of cubic meters $\left(\mathrm{m}^{-3}\right)$, and in the flood season the productivity of water is generally measured in terms of hectare (ha). Thus to find overall productivity, a common unit of measurement is needed.

To measure aggregate water productivity in terms of cubic meters $\left(\mathrm{m}^{-3}\right)$, the water productivity for living aquatic resources (equation 17) needs to be converted in terms of cubic meters $\left(\mathrm{m}^{-3}\right)$ by adjusting cubic meters $\left(\mathrm{m}^{-3}\right)$ of water available per hectare $\left(\mathrm{ha}^{-1}\right)$, and then be added with water productivity for rice (equation 9 ). The equation can be expressed as,

$$
\mathrm{WP}_{\mathrm{A}}\left(\mathrm{Kg} \mathrm{m}^{-3}\right)=\frac{Q_{1}(K g)+Q_{2}(K g)+Q_{3}(K g)+Q_{4}(K g)}{\mathrm{A}_{\mathrm{wr}}\left(\mathrm{m}^{3}\right)}+\frac{Q_{y}(K g)}{W C\left(m^{3}\right)}
$$

Where,

$\mathrm{WP}_{\mathrm{A}}=$ per cubic meters $\left(\mathrm{m}^{-3}\right)$ aggregate $\mathrm{WP}$ in terms of kilogram $(\mathrm{Kg})$

$\mathrm{Q}_{1} \quad=$ net output of culturable fish in terms of kilogram $(\mathrm{Kg})$

$\mathrm{Q}_{2} \quad=$ net output of wild fish in terms of kilogram $(\mathrm{Kg})$

$\mathrm{Q}_{3} \quad=$ net output of snails in terms of kilogram $(\mathrm{Kg})$ 
$\mathrm{Q}_{4} \quad=$ net output of aquatic plants in terms of kilogram $(\mathrm{Kg})$

$\mathrm{A}_{\mathrm{wr}}\left(\mathrm{m}^{3}\right)=$ cubic meters $\left(\mathrm{m}^{-3}\right)$ of water available in seasonal floodplain beels

$Q_{y} \quad=$ yield of rice crop in terms of kilogram $(\mathrm{Kg})$

$\mathrm{WC}\left(\mathrm{m}^{3}\right)=$ consumption of depleted water for rice crop in terms of cubic meters $\left(\mathrm{m}^{-3}\right)$

Similarly, to measure aggregate water productivity in terms of hectare $\left(\mathrm{ha}^{-1}\right)$, water productivity for rice (equation 9) needs to be converted in terms of hectare $\left(\mathrm{ha}^{-1}\right)$ by adjusting cubic meters $\left(\mathrm{m}^{-3}\right)$ of water required for per hectare $\left(\mathrm{ha}^{-1}\right)$ production, and then be added with water productivity for living aquatic resources (equation 17). The equation can be expressed as,

$$
W P_{A}\left(K g \mathrm{ha}^{-1}\right)=\frac{Q_{1}(K g)+Q_{2}(K g)+Q_{3}(K g)+Q_{4}(K g)}{\mathrm{A}_{\mathrm{wr}}(\mathrm{ha})}+\frac{Q_{y}(K g)}{W C(\mathrm{ha})}
$$

Where,

$\mathrm{WP}_{\mathrm{A}}=$ per hectare $\left(\mathrm{ha}^{-1}\right)$ aggregate $\mathrm{WP}$ is terms of $\mathrm{Kg}$

$\mathrm{Q}_{1} \quad=$ net output of culturable fish in terms of kilogram $(\mathrm{Kg})$

$\mathrm{Q}_{2} \quad=$ net output of wild fish in terms of kilogram $(\mathrm{Kg})$

$\mathrm{Q}_{3} \quad=$ net output of snails in terms of kilogram $(\mathrm{Kg})$

$\mathrm{Q}_{4} \quad=$ net output of aquatic plants in terms of kilogram $(\mathrm{Kg})$

$A_{w r}(h a)=$ hectare (ha) area of seasonal floodplain beels

$Q_{y} \quad=$ yield of rice crop in terms of kilogram $(\mathrm{Kg})$

$\mathrm{WC}(\mathrm{ha})=$ consumption of depleted water for rice crop in the area (ha)

Though, it can be expressed in common physical unit, it is not a proper measurement by convention. So, monetary value is a better alternative for measurement expression. If anyone of the equations 23 or 24 is converted in monetary value, the aggregate productivity of water for the full year is possible to measure. The form of the equation is as follows,

$$
\begin{aligned}
& \mathrm{WP}_{\mathrm{A}}\left(\$ \mathrm{~m}^{-3}\right)=\frac{Q_{v 1}(\$)+Q_{v 2}(\$)+Q_{v 3}(\$)+Q_{v 4}(\$)}{\mathrm{A}_{\mathrm{wr}}\left(\mathrm{m}^{3}\right)}+\frac{\mathrm{Q}_{\mathrm{v} 1}(\$)+\mathrm{Q}_{\mathrm{v} 2}(\$)}{W C\left(m^{3}\right)} \\
& W P_{A}\left(\$ \mathrm{ha}^{-1}\right)=\frac{Q_{v 1}(\$)+Q_{v 2}(\$)+Q_{v 3}(\$)+Q_{v 4}(\$)}{\mathrm{A}_{\mathrm{wr}}(\mathrm{ha})}+\frac{\mathrm{Q}_{\mathrm{v} 1}(\$)+\mathrm{Q}_{\mathrm{v} 2}(\$)}{W C(\mathrm{ha})}
\end{aligned}
$$

Where,

$\mathrm{WP}_{\mathrm{A}}=$ per cubic meters $\left(\mathrm{m}^{-3}\right)$ or per hectare $\left(\mathrm{ha}^{-1}\right)$ aggregate WP in terms of value

$\mathrm{Qv}_{1} \quad=$ net return of culturable fish in terms of value

$\mathrm{Qv}_{2}=$ net output of wild fish in terms of value

$\mathrm{Qv}_{3}=$ net output of snails in terms of value

$\mathrm{Qv}_{4}=$ net output of aquatic plants in terms of value

$\mathrm{A}_{\mathrm{wr}}\left(\mathrm{m}^{3}\right)=$ cubic meters $\left(\mathrm{m}^{-3}\right)$ of water available in seasonal floodplain beels 
$A_{w r}(h a)=$ hectare (ha) area of seasonal floodplain beels

$Q_{V 1} \quad=$ net return of rice yield in terms of value

$Q_{V 2} \quad=$ net return of product in terms of value

$\mathrm{WC}\left(\mathrm{m}^{3}\right)=$ consumption of depleted water for rice crop in terms of cubic meters $\left(\mathrm{m}^{-3}\right)$

$\mathrm{WC}(\mathrm{ha})=$ consumption of depleted water for rice crop in the area (ha)

\section{Conclusion}

Population growth and water scarcity are closely interrelated as growing population have to depend on fixed water resource to meet up their requirements. This rapidly growing population are competing for fresh water and food that is to be met up by limited available resources with prevailing technological development. It is needed to produce more and more food from limited land and water resource. Again the country's demography, climate, land and agricultural pattern also require better water management to enhance the water use efficiency. These evolve the issue of raising water productivity to fulfil the ever increasing demands and for achieving economic development.

In last few decades researchers have devoted much effort on quantifying crop water productivity at various scale levels and raising crop water productivity by various water saving measures that refer to technologies that lead to reduction in the water supply to the field of interest. Substantial progress has been achieved in this field but the researchers most often overlooked the potential and existing water resources to measure water productivity. Recent studies have paid attention on valuating wet lands taking into account its enormous uses and benefits. Economic valuations of these aquatic ecosystems are also being related with integrated management approaches in order to promote human welfare and sustainable development of natural resources. To improve water productivity it is needed to know about the opportunities to work on and the proper management options for water.

Floodplains areas are big lands with huge scope to use water more efficiently. In the floodplain area water dries in one season and becomes flooded in another season. Thus, a combined valuation of aquatic resources and crop production in two different seasons can provide more efficient use of water. This study deals with how to measure annual aggregate water productivity during wet season by introducing fish culture and during dry season by valuating agriculture in a floodplain beel area. This study discusses the measurement of water productivity in terms of physical (yield of outputs against volume of water) and combined physical and economic (value of outputs against volume of water) ways. The paper will help the integrated water resource management for a better and effective usage of water as well as ensuring conservation and propagation of water resources.

\section{Acknowledgements}

The authors would like to acknowledge the support for this research from the WorldFish Center, Malaysian Commonwealth Scholarship (MCS), and the project of "Transforming Rural Economy (AP-2014-017)" headed by Prof Chamhuri Siwar. 


\section{References}

Alam, M. S., Hossain, M. S., 2007. "Beel”. Banglapedia. Asiatic Society of Bangladesh. http://banglapedia.search.com.bd/HT/B_0382.htm. (23rd nov. 2007)

Ali, M.H., Talukder, M.S.U., 2008. Increasing water productivity in crop production. A synthesis of agricultural water management. 95(11), 1201-1213.

Amadi, A.O., 1991. "Recipe for Productivity Improvement" in Umeh, P.O.C. et al (1991) "Increasing Productivity in Nigeria" Proceedings of the First National Conference on Productivity $3^{\text {rd }}$ December 1987, National Productivity Centre, Macmillan, Nigeria, pp $98-106$.

Antle, M. J., Capalbo, S. M., 1988. "An Introduction to Recent Development in Production Theory and Productivity Measurement" in Capalbo, S.M. and Antle, M.J. ' Agricultural Productivity: Measurement and Explanation' Resources For the Future, Inc., Washington, DC.

Barker, R., Dawe, D., Inocencio, A., 2003. Economics of water productivity in managing water for agriculture. In Kijne, J. W.; Barker, R.; Molden. D. (Eds.), Water productivity in agriculture: Limits and opportunities for improvement. Wallingford, UK; Colombo, Sri Lanka: CABI; IWMI, pp.19-35.

Bastiaanssen, W.G.M., van Dam , J.C., Droogers, P., 2003. Introduction. In Dam, J.C. van, and R.S. Malik (Eds.), 2003. Water productivity of irrigated crops in Sirsa district, India. Integration of remote sensing, crop and soil models and geographical information systems. WATPRO final report, including CD-ROM. 6, 11-19.

Bateman,I.J. Carson, R.T. Day, B. Hanemann, M. Hanley, N. , Hett T. 2002. Economic valuation with stated preference techniques: A manual, Edward Elgar, Cheltenham, UK.

Bessembinder, J.J.E., Leffelaar, P.A., Dhindwal, A.S., Ponsioen, T.C., 2005. Which crop and which drop, and the scope for improvement of water productivity. Agric. Water Manage. 73 (2), 113-130.

Block, S.A.,1994. A new view of agricultural productivity in sub-saharan Africa. Amer. J. Agri. Econ. 76(3), 619-624.

Bondari, K., Treadgill, E.D., Bender, J.A., 1983. Tilapia culture in conjunction with irrigation and urban farming. International Symposium on Tilapa in Aquaculture. Tel Aviv University Press. Tel Aviv, Israel, pp 484-493.

Bouman, B.A.M., 2007 .A conceptual framework for the improvement of crop water productivity at different spatial scales. Agricultural Systems 93, 43-60.

Bowen, W. T., 2003. Water Productivity and Potato Cultivation. Water Productivity in Agriculture: Limits and Opportunities for Improvement. CABI Publishing, CAB International, Wallingford, Oxon, OX10 8DE, UK.

Bowen, W., Cabrera, H., Barrera, V., Baigorria, G., 1999. Simulating the response of potato to applied nitrogen. In: CIP Program Report 1997-1998. International Potato Center, Lima, Peru, pp 381-386.

Cai, X., Rosegrant, M., 2003. World water productivity: Current situation and future options. In: Kijne, J.W., Barker, R. and Molden, D. (Eds.) Water Productivity in Agriculture: Limits and Opportunities for Improvement. CABI, Wallingford, pp 163-178.

D'Silva, A.M., Maughan, O.E., 1994. Multiple use of water: integration of fish culture and tree growing. Agroforestry Syst. 26, 1-7. 
Dawe, D., Dobermann, A., 1999. Defining productivity and yield. IRRI Discussion Paper Series No. 33. Manila (Philippines): International Rice Research Institute, p 13.

Dey, M. M., Prein, M. 2004. Increasing and sustaining the productivity of fish and rice in the flood-prone ecosystems in South and Southeast Asia. Final Report to IFAD. WorldFish Center, Penang, pp 1-94.

Droogers, P., Bastiaanssen,W.G.M. 2002. Irrigation performance using hydrological and remote sensing modelling. J. of Irrigation and Drainage Engineering 128, 11-18.

Dugan, P.J., Dey, M.M , Sugunan, V.V., 2006. Fisheries and Water productivity in tropical river basins:enhancing food security and livelihoods by managing water for fish. Agricultural Water Productivity. 80, 262-275.

FAO., 2003. Raising water productivity. Issues in world agriculture 2001-2004, Spotlight 2001-2004. http://www.fao.org/AG/magazine/0303sp2.htm, (4th July 2007)

Griffin, T.S., Johnson, B.S., Ritchie, J.T., 1995. A Simulation Model for Potato Growth and Development: SUBSTOR-Potato Version 2.0. IBSNAT Research Support Series 02, Department of Agronomy and Soil Science, University of Hawaii, Honolulu, Hawaii.

Guerra, L.C., Bhuiyan S.I., Tuong T.P., Barker R., 1998. Producing more rice with less water from irrigated systems. SWIM Paper 5. Sri Lanka, Colombo: International Water Management Institute.

Hossain, M.I., Siwar, C., Mokthar, M., Dey, M.M., Jaafar, A.H., and Alam, M.M. 2013. Productivity of Water for Boro Rice Crop Production: Study on Floodplain Beels in Rajshahi, Bangladesh, Journal of Bio-Science, 21, 123-136.

Hossain, M.I., Alam, M.M., Siwar, C., Dey, M.M., Mokthar, M., and Jaafar, A.H. 2015. Challenges of Community based Fish Culture Program: Case Study on Floodplain Beel Mail in Rajshahi, Bangladesh. Journal of the Institute of Bangladesh Studies, 36, 129-136.

Henry, E. I., Henry, F. M., Andrew, K.P.R., Tarimoa, Baanda, A. S., 2006. Crop water productivity of an irrigated maize crop in Mkoji sub-catchment of the Great Ruaha River Basin, Tanzania. Agricultural Water Management. 85(1-2), 141150.

Iyaniwura, O., Osoba, A.M., 1983 "Measuring Productivity; Conceptual and Statistical Problems: Improvement of Statistics" in Osoba A.M. (ed.) 'Productivity in Nigeria' Proceedings of a National Conference' NISER, Ibadan.

Khoo, K.H., Tan, E.S.P., 1980. Review of the rice-fish culture in Asia,. In: Integrated Agriculture-Aquaculture Farming Systems. p. 1-14. R.S.V. Pullin , Z.H.Shehadeh (Eds.). ICLARM Conf. Proc. 4, Manila, Philippines.

Kijne, C. J., 1996. Water and salt balances for irrigated agriculture in Pakistan. Research Report 6. Colombo, Sri Lanka: International Irrigation Management Institute.

Liu, J., Zehnder, A.J. B., Yang, H., 2008. Drops for crops: Modelling crop water productivity on a global scale. Global NEST Journal. 10 (3), 295-300.

Mahdian, M.H., Gallichand, J., 1995. Validation of the SUBSTOR model for simulating soil water content.Transactions of the ASAE 38, 513-520. Ritchie, J.T., Griffin, T.S. and Johnson, B.S. (1995) SUBSTOR: functional model of potato growth, development and yield. In: Kabat, P. et al. (eds) Modelling and Parameterization 
of the Soil-Plant-Atmosphere System: a Comparison of Potato Growth Models. Wageningen Pers., Wageningen, pp. 401-435.

Molden, D., 1997. Accounting for water use and productivity. SWIM Paper 1. Colombo, Sri Lanka: International Irrigation Management Institute.

Molden, D., Sakthivadive, R., 1999. Water Accounting to Assess Use and Productivity of Water. International Journal of Water Resources Development. 15, 55-71.

Molden, D., Murray-Rust, H., Sakthivadivel R., Makin, I., 2001. A water productivity framework for understanding and action. Workshop on Water productivity. Wadduwa, Sri Lanka, November 12 and 13, 2001.

Molden, D.J., Murray-Rust, H., Sakthivadivel, R., Makin, I., 2003. A water productivity framework for understanding and action. In. Jacob Kijne, Randolph Barker and David Molden (Eds.) Water productivity in agriculture: limits and opportunities for improvement. IWMI-CABI, Wallingford, UK, pp 1-19.

Olaoye, A. O., 1985. "Total Factor Productivity Trends in Nigerian Manufacturing" Nigerian Journal of Economic and Social Studies. 27 (3), 317-345.

Oyeranti, O. A., 2000. Concept and Measurement of Productivity in Productivity and Capacity Building in Nigeria, Proceedings of the Ninth Annual Conference of the Zonal Research Units of the Central Bank of Nigeria, Abeokuta, pp 16-35.

Pearce, David, 1993. "Natural resources, growth and development: Natural resources, growth and development: Economics, Ecology and Resource Scarcity. Clement Tisdell, Praeger, New York, 1990. pp 186" Ecological Economics. 7(1), 78-79.

Pimentel, D., Berger, B., Filiberto, D., Newton, M., Wolfe, B., Karabinakis, E., Clark, S., Poon, E., Abbett, E., Nandagopal, S., 2004. Water resources: agricultural and environmental issues. Bioscience. 54 (10), 909-918.

Powell, W., Gabe., 2009. Identifying Land Use/Land Cover (LULC) Using National Agriculture Imagery Program (NAIP) Data as a Hydrologic Model Input for Local Flood Plain Management. Applied Research Project, Texas State University. http://ecommons.txstate.edu/arp/296, (6 ${ }^{\text {th }}$ May 2007).

Randall, A.G., 1991. Shallow tertiary gas production, Powder River Basin, Wyoming. The Coalbed Methane, pp 13-16.

Rashidi, M., Gholami, M., 2008. Review of crop water productivity values for tomato, potato, melon, watermelon and cantaloupe in Iran. Int. J. Agri. Biol. 10, 432-6.

Renwick, M. E., 2001. Valuing water in irrigated agriculture and reservoir fisheries: A multiple-use irrigation system in Sri Lanka. Research Report 51. Colombo, Sri Lanka: International Water Management Institute.

Rijsberman, F.R., 2006. Water scarcity: fact or fiction? Agricultural Water Management. 80, 5-22.

Ritchie, J.T., Griffin, T.S. and Johnson, B.S., 1995. SUBSTOR: functional model of potato growth, development and yield. In: Kabat, P. et al. (eds) Modelling and Parameterization of the Soil-Plant-Atmosphere System: a Comparison of Potato Growth Models. Wageningen Pers., Wageningen, pp 401-435.

Seckler, D., Molden D., Sakthivadivel., R., 2003. The concept of efficiency in waterresources management and policy. In: Kijne et al. eds. 2003. Water Productivity in Agriculture: Limits and Opportunities for Improvement. CABI Publishing, Wallingford, UK. pp 37-51.

Senzanje, A., Chimunhu, T. , Zirebwa, J., 2005. Assessment of water productivity trends for parastatal agricultural operations - case of Middle Sabi Estate, Zimbabwe. Physics and Chemistry of the Earth. 30, 767-771. 
Sharma, B. R., 2006. Crop Water Requirements and Water Productivity: Concepts and Practices, in College of Agricultural Engineering, Punjab Agricultural University, Ludhiana.

Travasso, M.I., Caldiz, D.O., Saluzzo, J.A., 1997. Yield prediction using the SUBSTOR-Potato model under Argentinian conditions. Potato Research. 39, 305-312.

Vazifedoust, M., van Dam, J.C., Feddes, R.A., M. Feizi., 2008. Increasing water productivity of irrigated crops under limited water supply at field scale. Agricultural water management. 95, $89-102$.

Viets Jr., F.G., 1962. Fertilizers and the efficient use of water. Advances in Agronomy. $14,223-264$. 